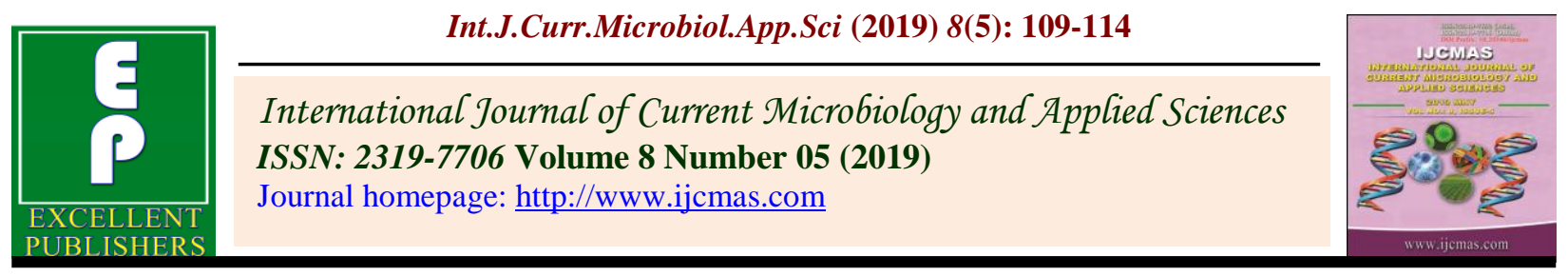

Case Study

https://doi.org/10.20546/ijcmas.2019.805.014

\title{
Pyothorax in Cats - A Review of Seven Cases
}

\author{
E. Venkatesakumar*, G. Vijayakumar and S. Sivaraman \\ Department of Veterinary Clinical Medicine, Veterinary College and Research Institute, \\ Namakkal, TANUVAS, Tamilnadu, India \\ *Corresponding author
}

A B S T R A C T

\begin{tabular}{|l|}
\hline Key w ord s \\
Cat, Pyothorax, \\
Thoracocentesis \\
\hline Article Info \\
\hline Accepted: \\
04 April 2019 \\
Available Online: \\
10 May 2019 \\
\hline
\end{tabular}

\section{Introduction}

Pyothorax or thoracic empyema is characterized by an accumulation of septic exudate in the thoracic cavity (Ettinger and Feldman, 2010). It is a life-threatening emergency condition in cats. Pyothorax is more frequently seen in cats than in dogs (Barrs et al., 2005). Underlying causes and treatment recommendations vary greatly between cases (Gorris et al., 2017a). Penetrating thoracic wounds, extension from underlying pulmonary infection, migrating foreign bodies, haematogenous spread of bacterial infection, pulmonary abscess, neoplasia and iatrogenic causes have been implicated for feline pyothorax (Fossum, 2000). Thoracocentesis and cytological evaluation of pleural fluid will be useful to diagnose pyothorax (Murphy and Papasouliotis, 2011; Epstein, 2014). Prognosis of feline pyothorax is fair to good if early intervention is started with appropriate antibiotic therapy and drainage of purulent materials from pleural space by thoracocentesis, otherwise leading to guarded prognosis.

\section{Materials and Methods}

Seven non-descript cats were presented to small animal outpatient unit of Veterinary College and Research Institute Hospital, Namakkal with history of severe respiratory distress, oral breathing and wide based stance were selected for the study. Detailed clinical examination was done. Two milliliters of blood with EDTA and two milliliters of blood 
with clot activator were collected for haematological and serum biochemical evaluation. Radiography of thorax and echocardiography were done. Thoracocentesis was done on standing or sternal position. The fluid from the pleural space was aspirated by connecting $20 \mathrm{ml}$ syringe with three way stop cock. Collected fluid was subjected to cytological and cultural examinations. The animals were treated with amoxicillin+cloxacillin (@20 mg/kg bid s/c) and furosemide (@1 mg/kg bid s/c).

\section{Results and Discussion}

In the present study, age of the cats with pyothorax ranged between six months to four years however, Barrs et al., (2005) reported more incidence of pyothorax in middle-aged cats with a mean age of three to six years. In the present study, five male and two female cats were reported. Increased incidence of pyothorax in male cats was in consistent with early researchers. Outdoor male cats were more commonly affected probably because young male have a greater likelihood to roam and fight resulting in penetrating injuries (Demetriou et al., 2002; Waddell et al., 2002). In some studies, it had been suggested that aspiration of oropharyngeal flora with parapneumonic spread might be a more frequent cause of pyothorax than bite wounds (Barrs and Beatty, 2009).

Cats with pyothorax showed respiratory distress, oral breathing, abducted elbows, extended head/neck and inspiratory dyspnoea (Fig. 1). Only one male cat showed a lacerated wound in the right lower thorax (Fig. 2). Rectal temperature, pulse rate and respiratory rates were elevated in the cats. Gorris et al., (2017 b) observed fever, tachypnoea and inspiratory dyspnoea in cats with pyothorax. Auscultation of thorax revealed muffled lung and heart sounds over the thorax in cats with pyothorax was in accordance with early authors (Epstein, 2014; Gorris et al., 2017 b). Percussion over the thorax revealed dull sound. Leukocytosis with neutrophilia was observed in haematology. Total protein and albumin were reduced in three animals but all other cats showed increased globulin level. Other serum biochemical parameters namely blood urea nitrogen (BUN) and alanine amino transferase (ALT) were within the normal range. Demetriou et al., (2002) reported leukocytosis, hypoalbuminaemia and hyperglobulinaemia in pyothorax in cats; however, Gorris et al., (2017b) observed nonregenerative anaemia, mild lymphocytosis, severe neutrophenia, elevated urea.

Radiography revealed effusion in the pleural cavity obscuring the lung and cardiac silhouette. Dorsoventral radiography of thorax confirms the presence of pleural effusion (Beatty and Barrs, 2010) and the lateral radiography helps to detect loculations (Christie, 2010). Echocardiography showed effusion in the pleural cavity. All the cats with pyothorax showed normal cardiac function. Radiography and ultrasonography of thorax were useful in identifying pyothorax and to evaluate complete drainage of pleural fluid. Although thoracic radiography is more sensitive than ultrasonography in detecting small-volume pleural effusions, thoracic ultrasonography is a less invasive technique for the confirmation of a moderate to large volume of pleural effusion (Beatty and Barrs, 2010).

Pleural space of cat is lined by the visceral and parietal pleura. The serous membranes covering the outer surface of the lungs and inner surface of the thoracic cavity is dividing the pleural space into a left and a right hemithorax by the mediastinum (Ettinger and Feldman, 2010). The pleural space of normal cats usually contains pleural fluid of 0.1 $\mathrm{ml} / \mathrm{kg}$ bwt (Epstein, 2014). The production 
and absorption of this fluid represent a continuous process controlled by Starling's forces. Emergency thoracocentesis is necessary to drain the excess effusion from pleural space in cats (Beatty and Barrs, 2010). In the present study, all cats showed bilateral pyothorax and thoracocentesis was done in standing or sternal recumbency with minimal stress to cats (Fig. 3). Bilateral pleural effusion $(76 \%$ cats $)$, unilateral left-sided pleural effusion (16\% cats) and unilateral right-sided pleural effusion (8\% cats) were reported (Barrs et al., 2005). About $30 \mathrm{ml}$ to $110 \mathrm{ml}$ of fluid obtained from pleural space and were characterized by slightly viscid, cloudy aspirate from two cats with $\mathrm{pH} 6.5$ and thick, turbid, purulent exudates with $\mathrm{pH} 6.0$ in five cats were aspirated in the present study (Fig. 4). Cytological evaluation revealed sheet of degenerative neutrophils (Fig. 5) and was accordance with reported of Gorris et al., (2017a). Following thoracocentesis the dyspnoea, oral breathing reduced and animals were comfortable in breathing (Fig. 6).

The cultural examination of pleural fluid in the present study showed Staphylococcus sp in four animals and Streptococcus sp in three animals. Bacterial isolates from feline pyothorax consisted of gram-negative, facultative anaerobic rods and/or obligate anaerobic bacteria, representing oropharyngeal flora. Filamentous bacteria most commonly isolated in cats with pyothorax included Actinomyces spp. and Nocardia spp. (Barrs et al., 2005; Barrs and Beatty, 2009a). The antibiotic sensitivity test showed sensitivity to amoxicillin+cloxacillin, gentamicin and enrofloxacin.

The cats were administered with amoxicillin+cloxacillin $20 \mathrm{mg} / \mathrm{kg}$ bid s/c and furosemide @ $1 \mathrm{mg} / \mathrm{kg}$ bid s/c for three days followed by oral amoxicillin+cloxacillin for three days. Greene (2006) reported that amoxicillin-clavulanic acid (10-40 $\mathrm{mg} / \mathrm{kg}$ bid or tid) in cats is best antibiotic of choice for the management of pyothorax. The cats showing dyspnoea due to pleural effusion must be supplied with supplemental oxygen and fluid therapy (Gorris et al., 2017a). In the present study, all the cats showed remarkable recovery following thoracocentesis and antibiotic treatment.

Fig.1 Cat with pyothorax showing oral breathing

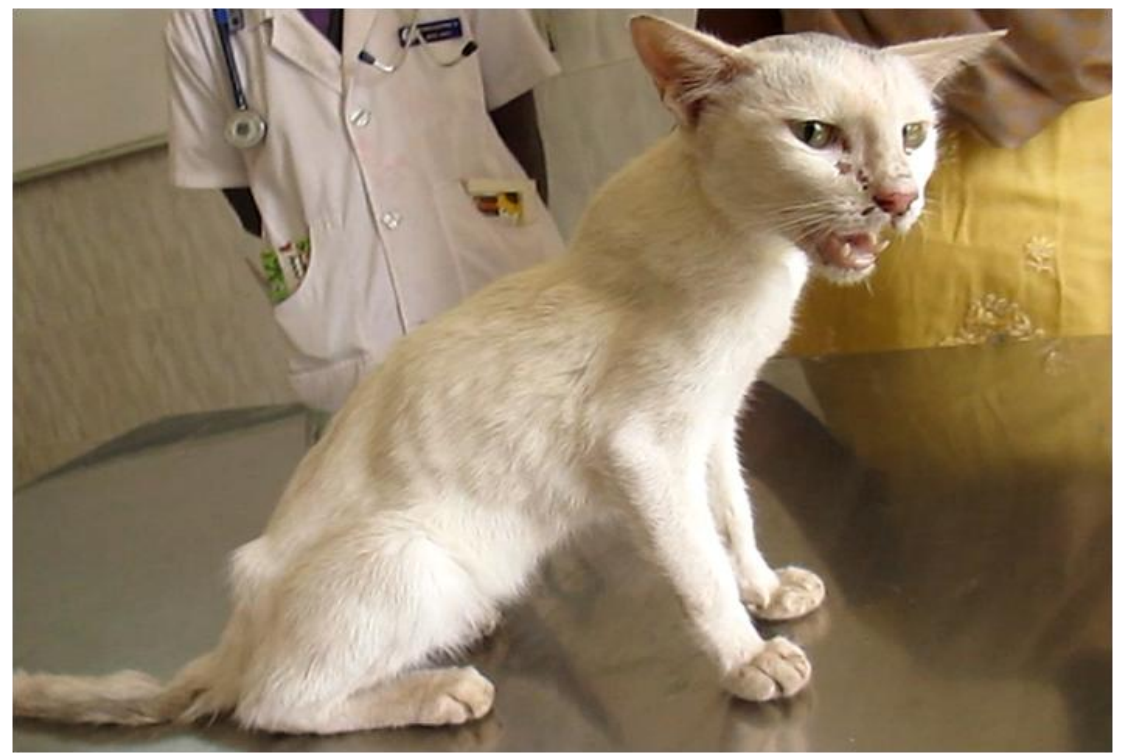


Fig.2 Cat affected with pyothorax having open wound in right lower thorax

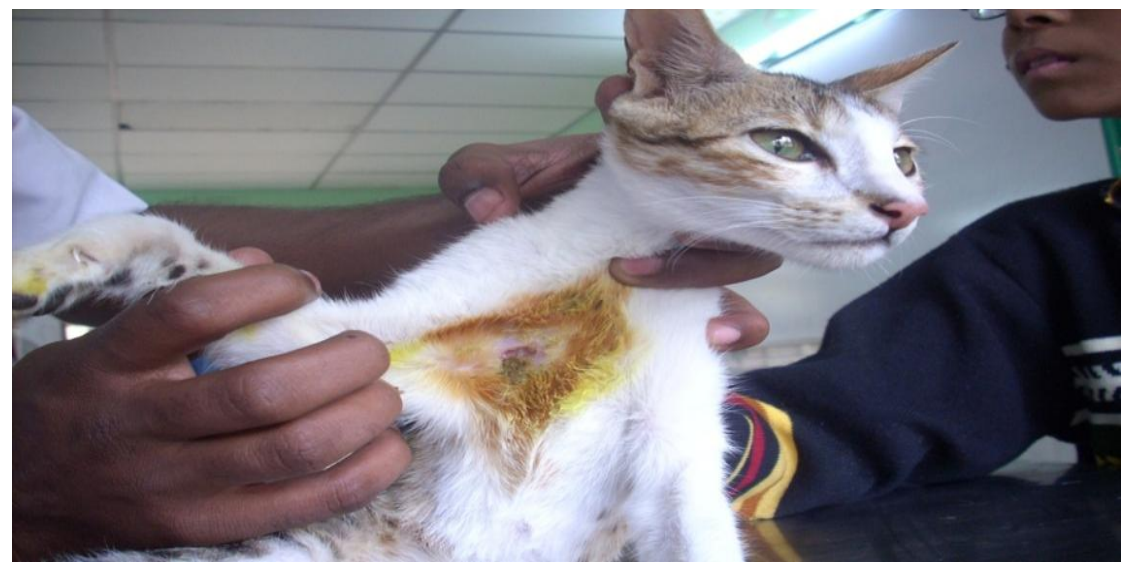

Fig.3 Thoracocentesis done at $7^{\text {th }}$ intercostal space in a cat with pyothorax showing purulent material

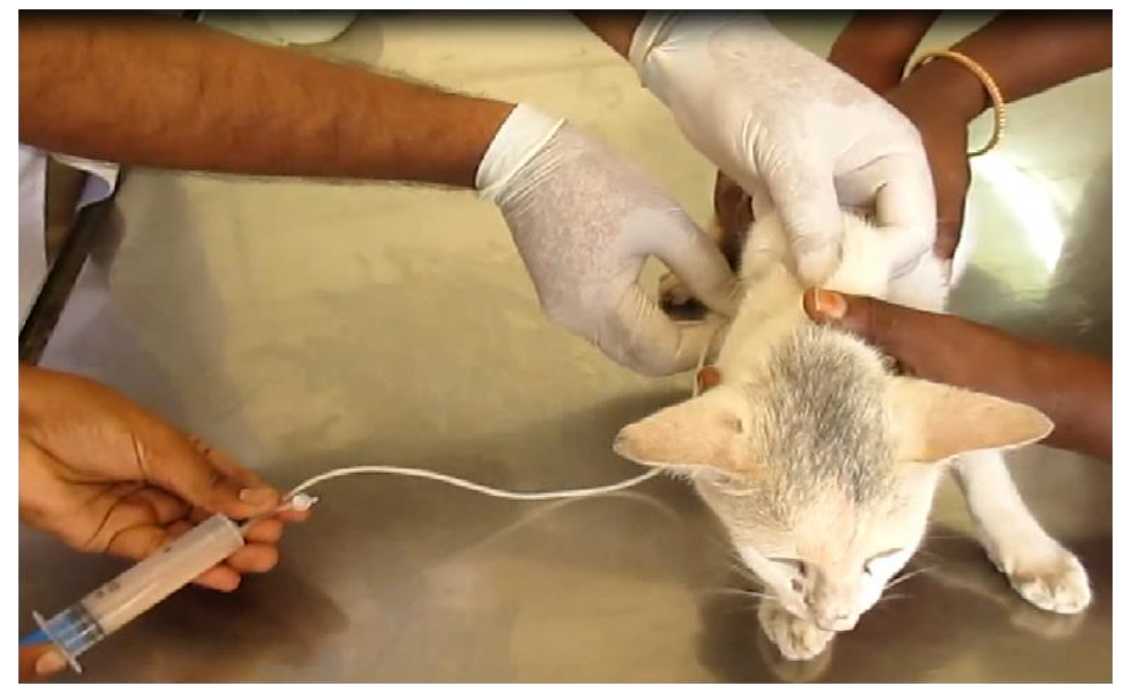

Fig.4 Thick, turbid, purulent pleural fluid

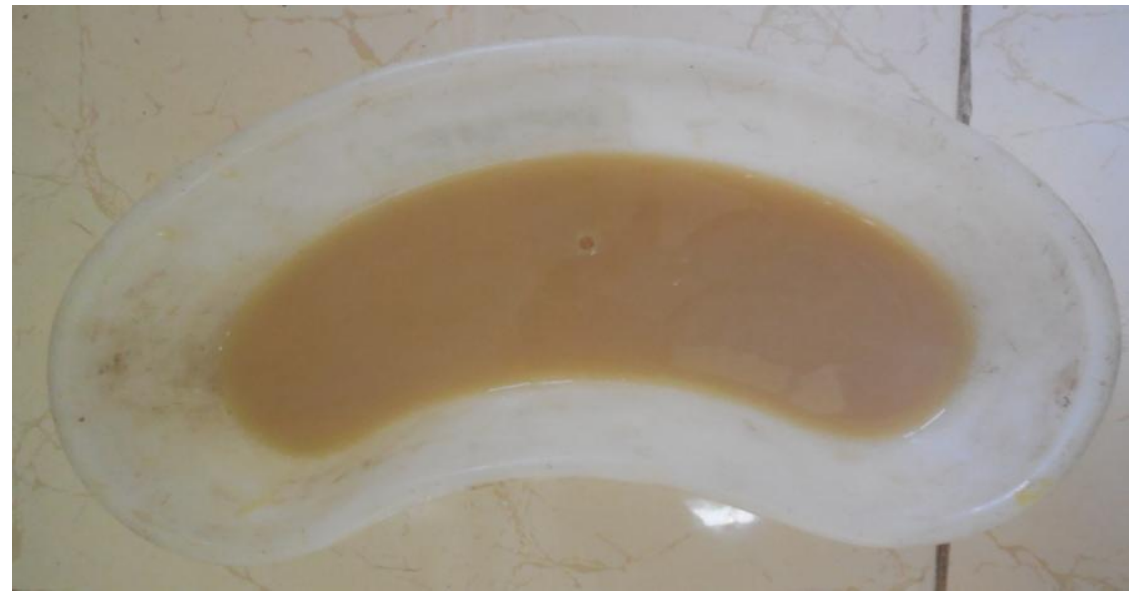


Fig.5 Cytology of pleural fluid showing sheet of degenerative neutrophils

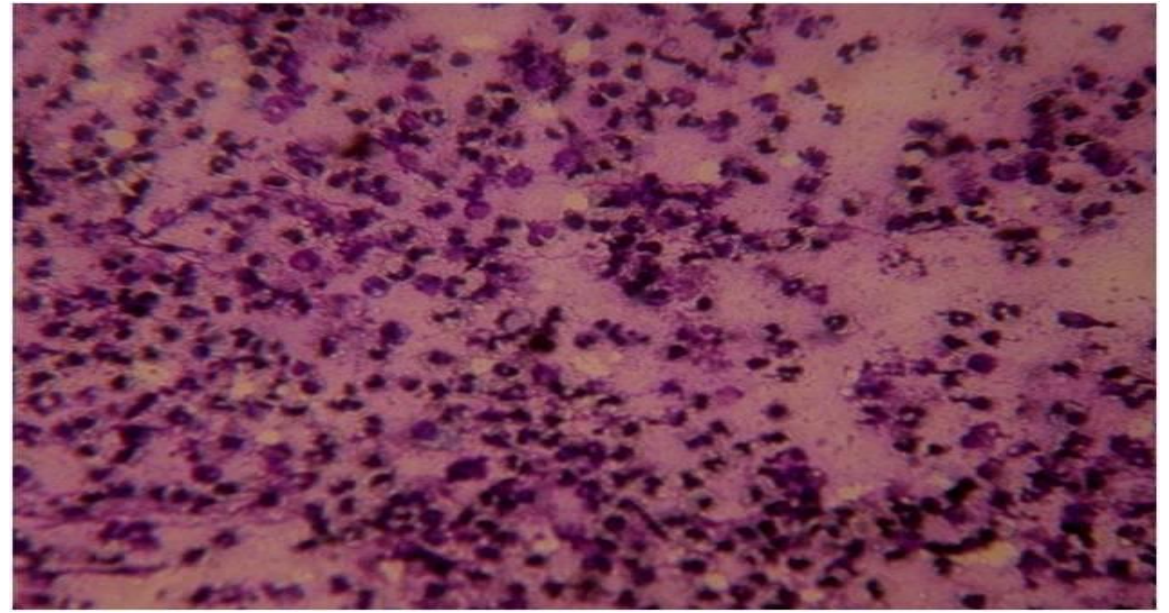

Fig.6 Respiratory distress reduced after thoracocentesis in cat with pyothorax

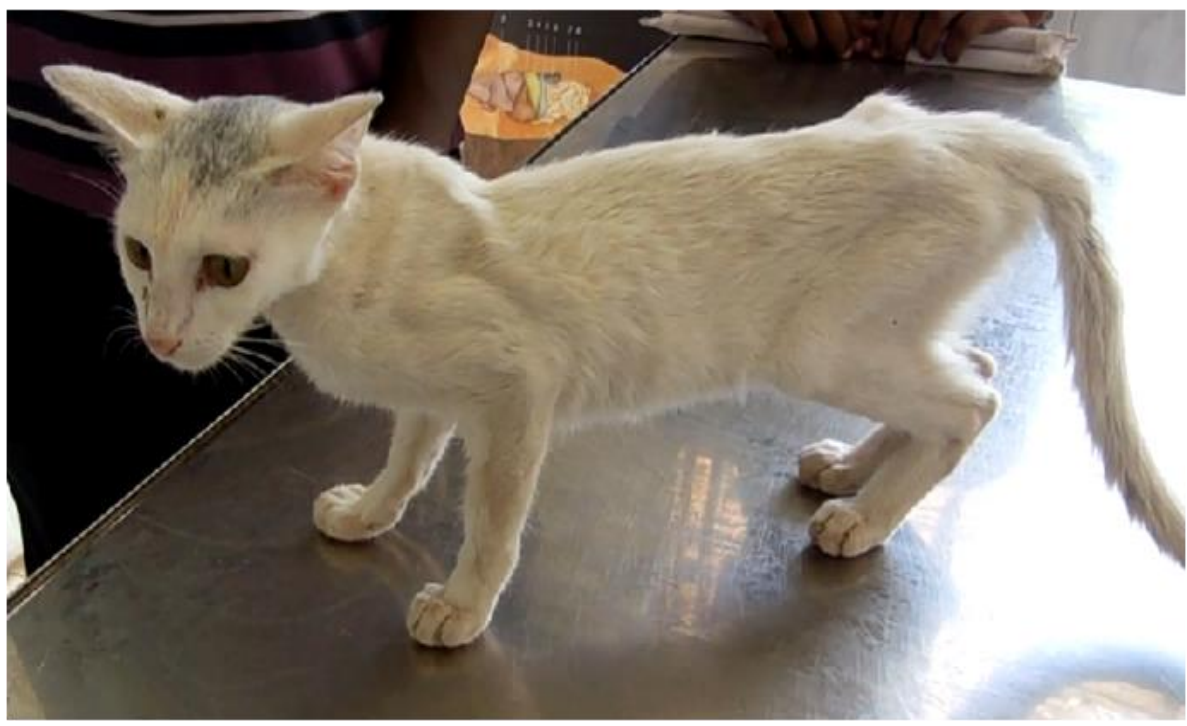

In conclusion, seven non-descript cats with pyothorax showed respiratory distress, oral breathing, extended head/neck, abducted elbow, dyspnoea and fever. They were diagnosed based on clinical signs, haematology, radiography and echocardiography. Thoracocentesis was done at $7^{\text {th }}$ intercostal space and aspirated purulent material from pleural space. Staphylococcus $s p$ and/or Streptococcus sp were isolated from pleural fluid. All the affected cats were successfully treated with amoxicillin+ cloxacillin and furosemide.

\section{Acknowledgement}

The authors are thankful to the Dean, Veterinary College and Research Institute, Namakkal for providing necessary facilities to carry out the work.

\section{References}

Barrs, V.R., Allan, G.S., Martin, P., Beatty, J.A. and Malik, R. 2005. Feline pyothorax: A retrospective study of 27 cases in Australia. J. Feline Med. 
Surg., 7: 211-222.

Barrs, V.R., and Beatty, J.A. 2009. Feline pyothorax - New insights into an old problem: Part 1. Ethiopathogenesis and diagnostic investigation. Vet. J., 179: 163-170.

Beatty, J.A., and Barrs, V. 2010. Pleural effusion in the cat. A practical approach to determining etiology. $J$. Feline Med. Surg., 12: 693-707.

Christie, N.A., (2010) Management of pleural space: Effusions and empyema. Surgical Clinics of North America, 90: 919-934.

Demetriou, J.L., Foale, R.D., Ladlow, J., McGrotty, Y., Faulkner J. and Kirby, B.M. 2002. Canine and feline pyothorax: a retrospective study of 50 cases in the United Kingdom and Ireland. J Small Anim Pract, 43: 388394.

Epstein, S.E., 2014. Exudative pleural disease in small animals. Vet. Clin. North Am. Small Anim. Pract., 44: 161-180.

Ettinger, S.J., and Feldman, E.C. 2010. Pleural and extrapleural disease. In: L.L. Ludwig, A.M. Simpson, E. Han (editors). Textbook of Veterinary Internal Medicine. Seventh Edition, Vol- I, Saunders Elsevier, Missouri, pp. 1125- 1137.

Gorris, F., Faut, S., Daminet, S., de Rooster, H., Saunders, J.H. and Paepe, D. 2017a. Pyothorax in cats and dogs. Vlaams Diergeneeskundig Tijdschrift, 86: 183-197.

Gorris, F., Faut, S., de Rooster, H., Vandervekens, E., Bosmans, T., Daminet, S., Smets, P. and Paepe, D. 2017b. Two cases of feline pyothorax: medical versus surgical treatment and associated challenges. Vlaams Diergeneeskundig Tijdschrift, 86: 162172.

Fossum, T.W., 2000. Pleural and extrapleural diseases, in Ettinger SJ, Feldman EC (eds): Textbook of Veterinary Internal Medicine, Philadelphia, WB Saunders, pp 1102-1111.

Greene, C.E., 2006. Section V: Clinical problems. In: Calvert C.A., Wall M. (editors). Infectious Diseases of the Dog and Cat. Third Edition, Saunders Elsevier, Missouri, pp.851.

Murphy, K., and Papasouliotis, K., 2011. Pleural effusions in dogs and cats. In Pract., 33: 462-469.

Waddell, L.S., Brady C.A., Drobatz K.J. 2002. Risk factors, prognostic indicators and outcome of pyothorax in cats, 80 cases (1986-1999). J. Am. Vet. Med. Assoc., 221:819-824.

Walker, A.L., Jang S.S., Hirsh D.C. 2000. Bacteria associated with pyothorax of dogs and cats, 98 cases (1989- 1998). J. Am. Vet. Med. Assoc., 216: 359-363.

\section{How to cite this article:}

Venkatesakumar, E., G. Vijayakumar and Sivaraman, S. 2019. Pyothorax in Cats - A Review of Seven Cases. Int.J.Curr.Microbiol.App.Sci. 8(05): 109-114. doi: https://doi.org/10.20546/ijcmas.2019.805.014 